\title{
Levels of airborne dust in furniture making factories in the High Wycombe area
}

\author{
R. F. HOUNAM and J. WILLIAMS \\ Health Physics and Medical Division, Atomic Energy Research Establishment, Harwell, Didcot, \\ Berkshire and S.E. London Technical College, Lewisham, London SE13
}

\begin{abstract}
Hounam, R. F. and Williams, J. (1974). British Journal of Industrial Medicine, 31, 1-9. Levels of airborne dust in furniture making factories in the High Wycombe area. A dust survey was carried out in five furniture making factories in, or in the vicinity of, High Wycombe. The results, which are among the first to be reported for the United Kingdom, have provided information on the concentrations and size distributions of airborne dust to which wood machinists are currently exposed. Although measured concentrations covered a wide range, the average concentration was similar to the threshold limit value of $5 \mathrm{mg} \mathrm{m}^{-3}$ provisionally recommended by the American Conference of Governmental Industrial Hygienists. A high proportion by mass of the airborne dust was of a size which will be deposited in the nasal passages on inhalation.
\end{abstract}

In recent years, it has been established that there is an excess of adenocarcinoma of the paranasal sinuses in woodworkers in the furniture industry (Acheson, Cowdell, Hadfield, and Macbeth, 1968; Hadfield, 1970). In addition to carcinoma of the nasal sinuses, occupational exposure to wood dust can produce pathological changes in the lungs (Michaels, 1967) and certain types of wood are known to produce an allergic response, an extreme case of which has been reported recently by Findley (1972). In connection with health hazards from exposure to wood dust, two investigations have been undertaken. The first, which is the subject of this paper, provides information on concentrations and particle size distributions of airborne dust currently produced in typical wood machining operations. The second, in which impairment of nasal mucociliary clearance in woodworkers was demonstrated, is described in the following paper (Black et al., 1974).

Information was obtained during a programme of air sampling in five furniture factories located in, or in the vicinity of, High Wycombe, Buckinghamshire.
There is little published information on dust levels in the furniture industry. Hanslian and Kadlec (1964) have reported values for the industry in Czechoslovakia, where average dust concentrations were $40 \mathrm{mg} \mathrm{m}^{-3}$ and peak concentrations as high as $200 \mathrm{mg} \mathrm{m}^{-3}$. They also reported that $90 \%$ of the particles were less than $5 \mu \mathrm{m}$ in diameter. These authors classified woods according to toxicity and recommended limits of 1,5 or $10 \mathrm{mg} \mathrm{m}^{-3}$, depending on the toxicity of wood being processed. A level of $5 \mathrm{mg} \mathrm{m}^{-3}$ (time-weighted average) has been provisionally recommended by the American Conference of Governmental Industrial Hygienists (1971) as a level which, on available evidence, will greatly minimize the risk of wood dust disease. The first systematic study of dust levels in the furniture industry in the United Kingdom was carried out by Williams (1972) a few months before the present survey, which supplements the results he obtained.

\section{Method}

Selection of factories

The factories visited were either in, or in the immediate 


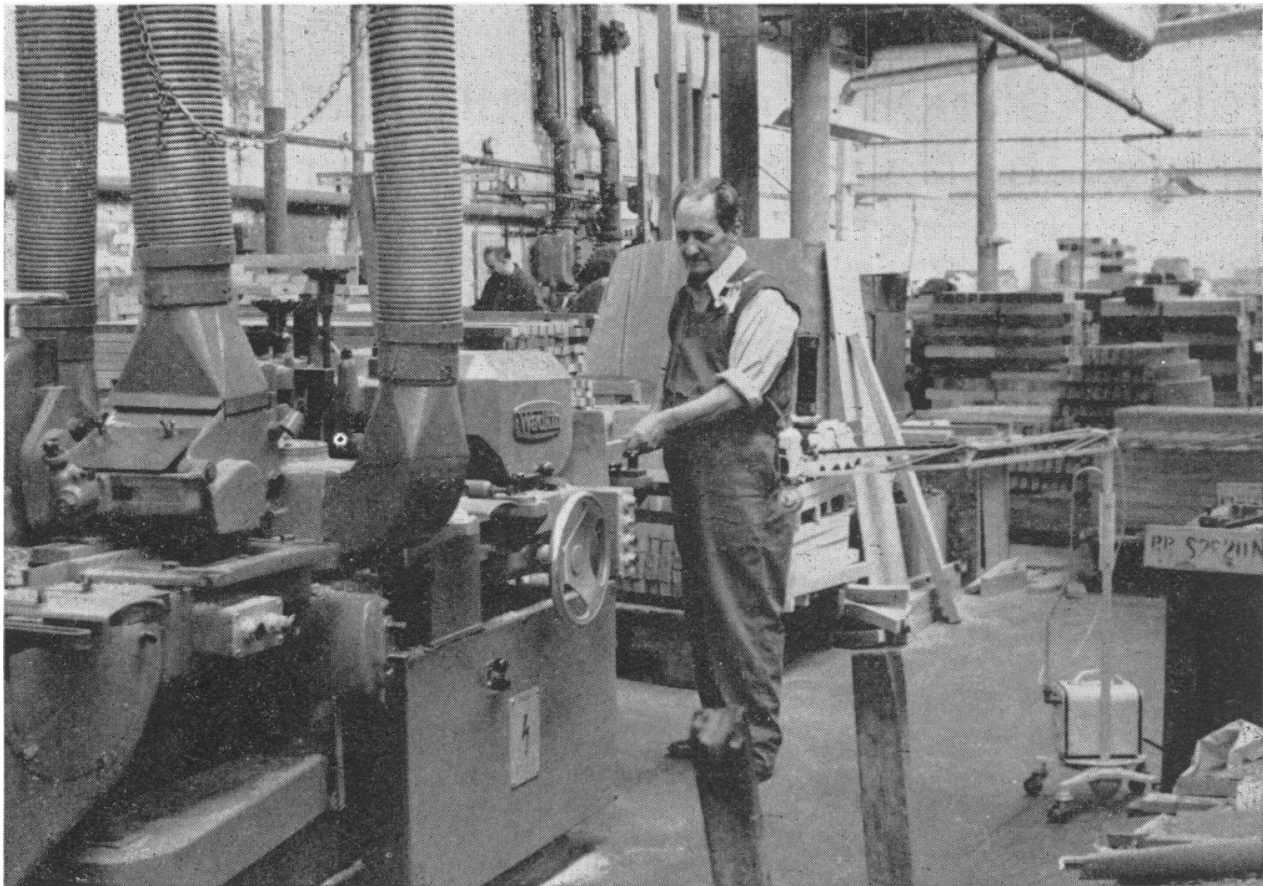

FIG. 1. Operating a four-cutter showing flexible connections to the extraction system, personal air sampler pump clipped on belt, sampling head attached to brace, and cascade centripeter nearby.

vicinity of, High Wycombe. They were selected to give a range of sizes and products as follows:

(a) a large factory producing solid wood chairs and furniture, primarily from beech and elm;

(b) a fairly large factory producing a variety of chairs and furniture in beech, elm, mahogany, and walnut;

(c) a fairly large factory producing a range of reproduction chairs and furniture in walnut, mahogany, and chipboard veneer;

(d) a medium-sized factory specializing in the production of veneered chipboard cabinets and cupboards;

(e) a smaller factory with a high output of walnut and mahogany chairs.

\section{Operations covered}

Almost all the operations in furniture making involve mechanized equipment, and most measurements of dust levels were made in the breathing zone of machine operators. The machining operations covered included:

(1) sawing planks with either band or circular saws in the conversion shop;

(2) smoothing wood with either planer or four-cutter;

(3) using a router or turning;

(4) using a spindle moulder;

(5) sanding shaped wood.

Dust levels were also measured in the breathing zone of workers assembling furniture, which occasionally involved sanding operations.

In all factories, machine shops were well ventilated by the extract system provided to remove chippings and dust produced by the machines.

\section{Sampling methods}

Following Williams (1972) the average concentrations of airborne dust to which operators were exposed during the working day were measured with the personal air sampler (Sherwood and Greenhalgh, 1960). This consists of a sampling head containing a filter paper attached to the worker's shirt collar, overall lapel or braces. The head is connected by a flexible tube to a small battery-operated pump clipped to the belt or hip pocket. Air is sampled in close proximity to the nose and mouth of the wearer. Figure 1 shows a four-cutter operator wearing a personal air sampler.

Workers employed on the operations listed above were selected at preliminary discussions with both management and unions at each factory. On the first day of the survey, samplers were fitted to the selected operators shortly after they started work at $\mathbf{0 7 . 3 0}$. Except for the lunch hour, they were worn continuously until collected just before the end of the working day at 16.30 . On the second day the procedure was repeated, so that at each factory two samples were taken on successive days covering the operations of each of six workers. The tasks carried out by a particular machinist might change during the working day, but as the sampler is attached to the man, the dust collected is representative of his actual exposure.

It was also considered important to obtain information 
on the size distribution of airborne dust produced in different machining operations to enable some estimation of its respirability to be made. Williams (1972) used two Hexhlet samplers (Wright, 1954) for this purpose, which enabled the total dust concentration and the respirable ( $<5 \mu \mathrm{m}$ ) fraction to be measured. In the present survey the cascade centripeter (Hounam and Sherwood, 1965) was employed, which separates airborne dust into four fractions and therefore gives more information on size distribution. After making corrections for wall losses, a value for the total dust concentration can also be derived. The calibration of the centripeter for spherical particles of different densities has been described by O'Connor (1973). At the sampling rate of $251 \mathrm{~min}^{-1}$ used in this survey, the effective cut-off sizes for unit density spheres are as follows:

$$
\begin{array}{lc}
\text { Stage 1 } & >13.65 \mu \mathrm{m} \\
\text { Stage 2 } & 4.15-13.65 \mu \mathrm{m} \\
\text { Stage 3 } & 1.53-4.15 \mu \mathrm{m} \\
\text { Stage 4 } & <1.53 \mu \mathrm{m}
\end{array}
$$

At each factory, sampling was carried out with the centripeter in the vicinity of all workers equipped with personal air samplers. The sampling head was located as close to the operator as possible without impeding access to his machine (Fig. 1). A few additional samples were taken with the centripeter to cover operations not included in the personal air sampler survey. Although the circular hood supplied with the centripeter was fitted, the access of 'inertials' was not completely prevented. Inertials are large particles or chippings with equivalent diameter exceeding $50 \mu \mathrm{m}$ which, in certain circumstances, are projected from the cutting edge of tools with such high velocity and in such profusion that collection by local extract may be incomplete.

In both the personal air sampler and the centripeter, dust was collected on preweighed Whatman GF/A glass fibre filters. After sampling, the filters were dried over silica gel for at least 24 hours before being reweighed. The sampling rates of the personal air sampler pumps were checked individually, and this information, together with the weight of dust collected, enabled the mass concentrations of airborne dust to be calculated. For examination of dust with the optical and scanning electron microscopes, some additional samples were collected on Millipore AA filters using the personal air sampler.

\section{Results}

The results of measurements of airborne dust with the personal air sampler are summarized in Table 1. Examination of the filters showed that in some cases inertials were present as well as fine airborne dust. Filters with different degrees of contamination by inertials are illustrated in Fig. 2, and samples whose weights were likely to be enhanced significantly by the presence of these relatively large particles are indicated in Table 1.

Measurements of total dust levels with the cascade centripeter are summarized in Table 2, which lists the range and mean values for each operation. The mean particle size distributions for the various operations covered are illustrated in Fig. 3, in which they are plotted in cumulative form on logprobability paper.

\section{Discussion}

Measurements with the personal air sampler When measuring dust levels in occupational situations, it is frequently found that a wide range of

\begin{tabular}{|c|c|c|c|c|c|c|c|c|}
\hline \multirow{2}{*}{ Factory } & \multirow{2}{*}{ Sample } & \multicolumn{7}{|c|}{ Operation } \\
\hline & & Band sawing & Planing & Routing & $\begin{array}{l}\text { Spindle } \\
\text { moulding }\end{array}$ & Sanding & Assembly & Turning \\
\hline $\mathbf{A}$ & $\begin{array}{l}\text { Day } 1 \\
\text { Day } 2\end{array}$ & $\begin{array}{r}20 \cdot 0^{1} \\
7 \cdot 3^{1}\end{array}$ & $\begin{array}{l}2 \cdot 0 \\
2 \cdot 4\end{array}$ & $\begin{array}{l}1 \cdot 8 \\
3 \cdot 8\end{array}$ & $\begin{array}{l}5 \cdot 8 \\
6 \cdot 3\end{array}$ & $\begin{array}{l}2 \cdot 4 \\
3 \cdot 6\end{array}$ & $\begin{array}{c}25 \cdot 5^{3} \\
2 \cdot 1\end{array}$ & - \\
\hline B & $\begin{array}{l}\text { Day } 1 \\
\text { Day } 2\end{array}$ & $\begin{array}{l}5 \cdot 0 \\
7 \cdot 3\end{array}$ & $\begin{array}{l}8 \cdot 5 \\
9 \cdot 1\end{array}$ & $\begin{array}{l}8 \cdot 6 \\
3 \cdot 7\end{array}$ & $\begin{array}{l}6 \cdot 5 \\
8 \cdot 4\end{array}$ & $\begin{array}{l}8 \cdot 2 \\
3 \cdot 2\end{array}$ & $\begin{array}{l}3 \cdot 5 \\
4 \cdot 4\end{array}$ & - \\
\hline C & $\begin{array}{l}\text { Day } 1 \\
\text { Day } 2\end{array}$ & $\begin{array}{l}1.0 \\
1.8\end{array}$ & $\begin{array}{l}1 \cdot 8 \\
2 \cdot 8\end{array}$ & $\begin{array}{l}3 \cdot 5 \\
3 \cdot 3\end{array}$ & $\begin{array}{l}1 \cdot 5 \\
4 \cdot 4\end{array}$ & $\begin{array}{l}2 \cdot 0 \\
2 \cdot 4\end{array}$ & $\begin{array}{l}3 \cdot 7 \\
4 \cdot 5\end{array}$ & - \\
\hline D & $\begin{array}{l}\text { Day } 1 \\
\text { Day } 2\end{array}$ & $\begin{array}{c}12 \cdot 5^{1,2} \\
9 \cdot 2^{1}\end{array}$ & $\begin{array}{l}3 \cdot 1 \\
6 \cdot 3^{1}\end{array}$ & $\begin{array}{r}94 \cdot 6^{1} \\
8 \cdot 2^{1}\end{array}$ & - & $\begin{array}{l}25 \cdot 2^{1} \\
22 \cdot 6\end{array}$ & $\begin{array}{l}5 \cdot 9 \\
7 \cdot 6\end{array}$ & - \\
\hline $\mathbf{E}$ & $\begin{array}{l}\text { Day } 1 \\
\text { Day } 2\end{array}$ & $\begin{array}{l}6 \cdot 5 \\
4 \cdot 1\end{array}$ & $\begin{array}{r}10 \cdot 9 \\
4 \cdot 1\end{array}$ & - & $\begin{array}{l}3 \cdot 2 \\
4 \cdot 4\end{array}$ & $\begin{array}{r}7 \cdot 9 \\
12 \cdot 2\end{array}$ & $\begin{array}{l}8 \cdot 2 \\
9 \cdot 8\end{array}$ & $\begin{array}{r}4 \cdot 6 \\
12 \cdot 5\end{array}$ \\
\hline
\end{tabular}

TABLE 1

Concentrations of Airborne Dust $\left(\mathrm{mg} \mathrm{m}^{-3}\right.$ ) Measured with the Personal Air Sampler AT FIVE FURNITURE FACTORIES

${ }^{1}$ Sample contained 'inertials' in addition to fine dust

- Includes circular as well as band sawing

${ }^{3}$ This operator was sanding table tops before assembly. 


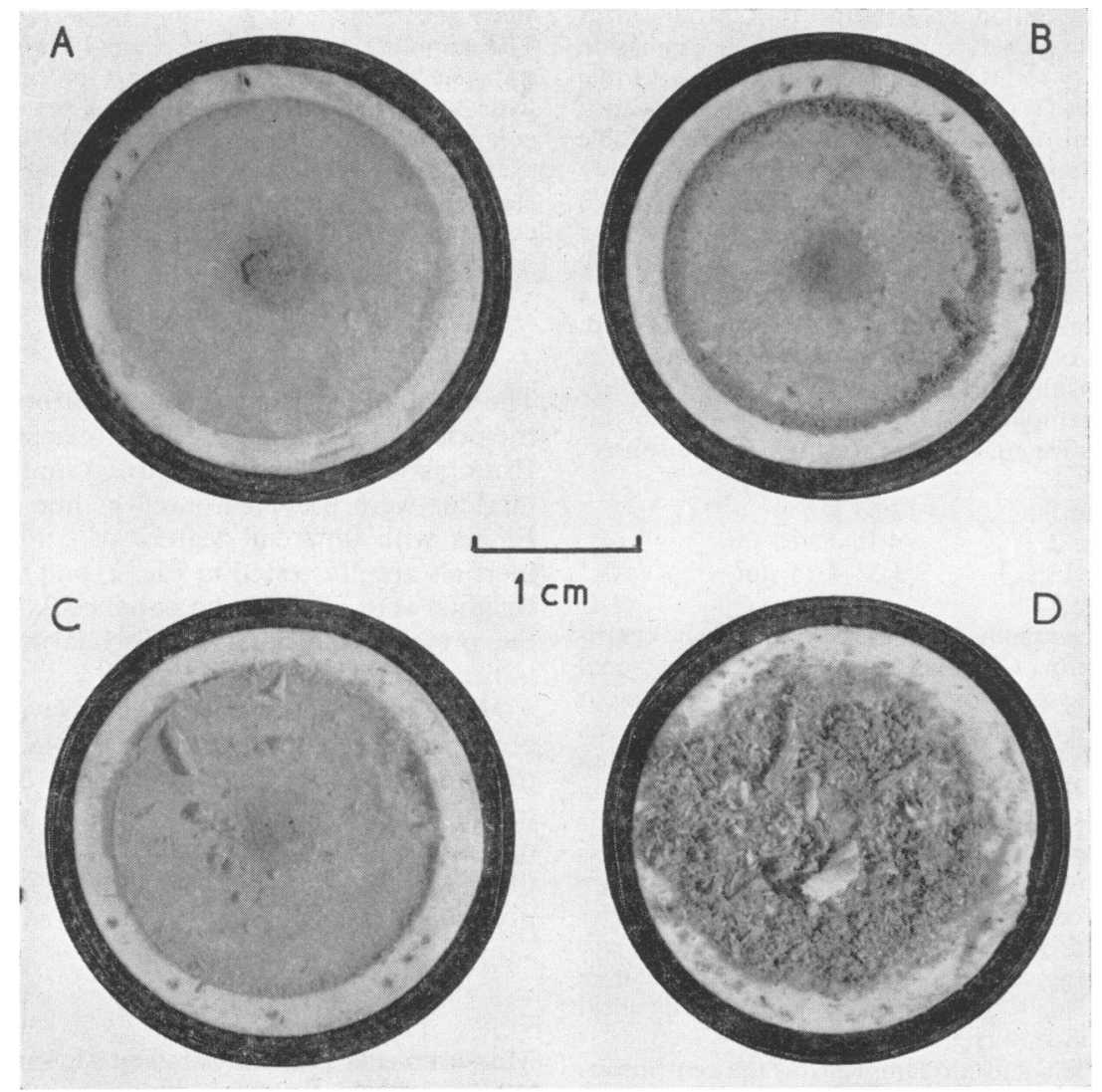

FIG. 2. Personal air sampler filter papers (A-D) showing different degrees of contamination by inertials (small chips and large wood dust particles $>50 \mu \mathrm{m}$ equivalent diameter).

TABLE 2

Concentrations and Mass Median Equivalent Diameters of Airborne Dust MEASURED With the CASCADE Centripeter

\begin{tabular}{|c|c|c|c|c|}
\hline \multirow{2}{*}{ Operation } & \multirow{2}{*}{$\begin{array}{c}\text { No. of } \\
\text { measurements }\end{array}$} & \multicolumn{2}{|c|}{$\begin{array}{l}\text { Dust concentration } \\
\left(m^{\prime} m^{-3}\right)\end{array}$} & \multirow{2}{*}{$\begin{array}{c}\text { Mass median equivalent } \\
\text { diameter }(\mu \mathrm{m})\end{array}$} \\
\hline & & Range & Mean & \\
\hline $\begin{array}{l}\text { Band/circular sawing } \\
\text { Planing } \\
\text { Routing } \\
\text { Spindle moulding } \\
\text { Sanding } \\
\text { Assembly } \\
\text { Turning } \\
\text { Shaping } \\
\text { Cyclone shed } \\
\text { Near bag filters }\end{array}$ & $\begin{array}{l}7 \\
5 \\
4 \\
6 \\
8 \\
6 \\
1 \\
1 \\
1 \\
1\end{array}$ & $\begin{array}{l}0 \cdot 8-100 \\
1 \cdot 7-9 \cdot 4 \\
2 \cdot 5-11 \cdot 3 \\
2 \cdot 0-36 \cdot 3 \\
0 \cdot 5-34 \cdot 3 \\
1 \cdot 3-5 \cdot 3 \\
- \\
- \\
-\end{array}$ & $\begin{array}{r}20 \cdot 1 \\
3 \cdot 6 \\
5 \cdot 5 \\
17 \cdot 0 \\
8.0 \\
3 \cdot 4 \\
9.0 \\
7 \cdot 2 \\
15 \cdot 2 \\
1.4\end{array}$ & $\begin{array}{r}11 \cdot 5 \\
9 \cdot 2 \\
10 \cdot 0 \\
10 \cdot 0 \\
8 \cdot 4 \\
7 \cdot 6 \\
11 \cdot 5 \\
8 \cdot 8 \\
5 \cdot 6 \\
6 \cdot 4\end{array}$ \\
\hline
\end{tabular}




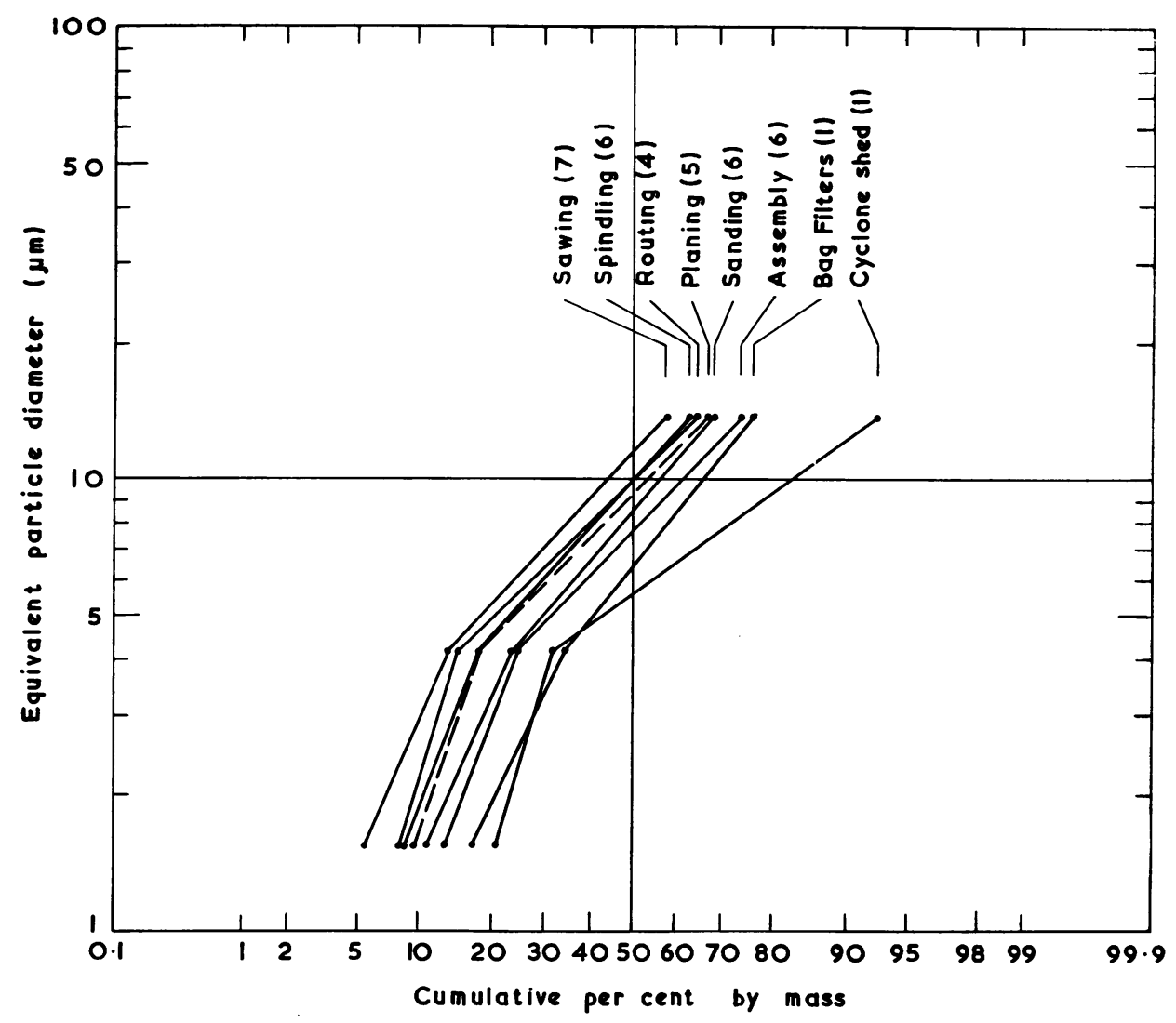

FIG. 3. Mean particle size distributions for various operations.

values are obtained and the present survey is no exception. In such cases it may be convenient to assume that the measurements belong to a population having a log-normal distribution (Hounam, 1965) and the results of the survey have been treated in this way. A cumulative plot on logprobability paper of measurements of airborne dust at all five factories (omitting samples whose weights were biased by the presence of inertials) is shown in Fig. 4. The distribution of sample weights appears to approximate to a log-normal distribution with a median value of $4.6 \mathrm{mg} \mathrm{m}^{-3}$. This represents the concentration that would most probably be found in a random sample. Because of the skew nature of the log-normal distribution a somewhat higher value, in this case $5.9 \mathrm{mg} \mathrm{m}^{-3}$, is found for the mean or average concentration of wood dust in the air of the machine shops. A more comprehensive sampling programme would be required to establish a meaningful average level for each factory and to establish whether there are significant differences in dust concentrations produced by the various operations.

Measurements with the cascade centripeter

A cumulative plot of the measurements of total airborne dust made with the cascade centripeter is included in Figure 4. The median value obtained $\left(4.2 \mathrm{mg} \mathrm{m}^{-3}\right)$ is similar to that derived from measurements with the personal air sampler. As might be expected, because of the shorter sampling times, the range of values is greater, and because of this the average concentration is found to be appreciably higher $\left(8.6 \mathrm{mg} \mathrm{m}^{-3}\right)$. It is usual for concentrations determined by static samplers to be lower than those obtained with the personal air sampler, but in this case the opposite applies. This can be accounted for by the fact that centripeter samples were taken only while machining was in progress, whereas personal air samplers covered a whole shift, including times when machining was suspended.

Although no details of sampling procedures are 


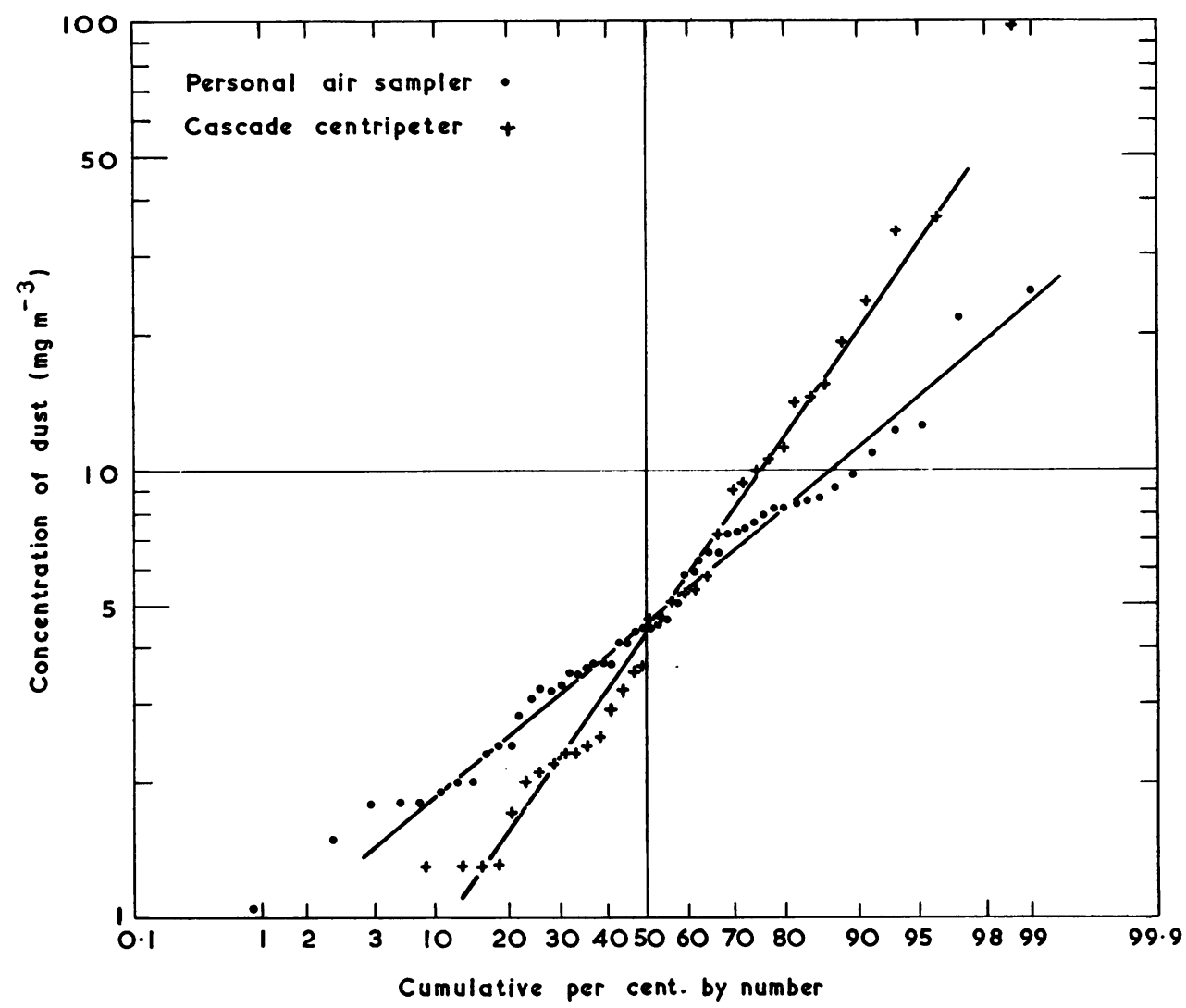

FIG. 4. Mass concentration distributions of airborne dust.

stipulated with the TLV of $5 \mathrm{mg} \mathrm{m}^{-3}$ (time-weighted average) provisionally adopted by the American Conference of Governmental Industrial Hygienists, the personal air sampler results are more appropriate for comparison because of the longer sampling period. Although the TLV was exceeded frequently, $90 \%$ of the measurements were less than $10 \mathrm{mg} \mathrm{m}^{-3}$.

The mean particle size distributions of dust produced in various operations and locations, shown in Fig. 3, indicate that the mass median equivalent diameters ranged from about 5 to $11 \mu \mathrm{m}$. As inertials were occasionally found on the final stage of the centripeter, the equivalent diameters may be underestimated to some extent. The coarsest dust was produced during sawing operations and the finest during sanding and assembly (which frequently involves sanding). Airborne dust in the vicinity of bag filters and in a cyclone house was finer than that in the vicinity of machines, presumably due to the removal of the coarser fractions. The fact that signifi- cant dust levels were detected in the vicinity of bag filters suggests that not all the dust was removed by the bags.

In $75 \%$ of the samples, the greatest weight of dust was found on the second stage of the centripeter (equivalent diameter 4.15-13.65 $\mu \mathrm{m}$ ). Material in this size range will be trapped very efficiently in the nasal passages. In general, less than $25 \%$ of the airborne dust was less than $5 \mu \mathrm{m}$ equivalent diameter and, as noted above, the presence of inertials on the final stage indicates that this is probably an over estimate. In many samples it was apparent that very little fine dust was collected on the final stage of the centripeter, and in some cases this had the grey appearance characteristic of general atmospheric pollution rather than of wood dust. Taking these factors into account, it seems likely that a relatively small proportion of the mass of airborne wood dust will penetrate to the alveolar region of the respiratory tract. 

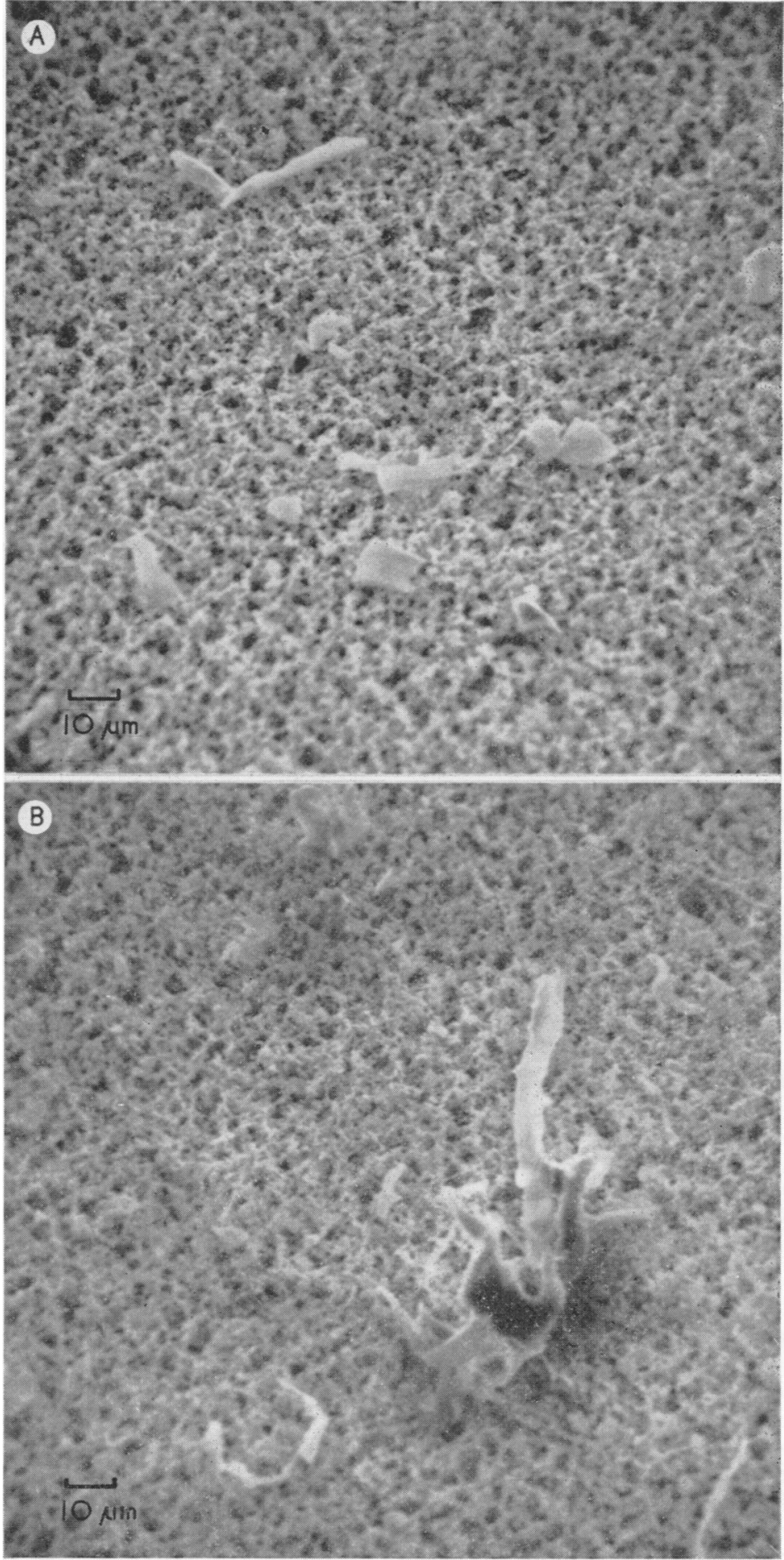

FIG. 5. Scanning electron microscope photographs of airborne wood dust ( $\times$ 760): (A) sample taken near spindle-mortiser; (B) sample taken near circular saw. 


\section{Microscopic examination of dust particles}

Particles of wood dust collected on membrane filters were rather large for convenient examination under the optical microscope. A better impression of their characteristics was obtained with the scanning electron microscope (Fig. 5) although the smaller particles do not show up particularly well against the surface of the filter. Photographs obtained with the scanning electron microscope provide visual confirmation that most particles of wood dust have dimensions greater than $5 \mu \mathrm{m}$. Many of the particles appear to be either fibrous or flaky in character, with a relatively high surface area to volume ratio.

\section{Conclusions}

The purpose of this survey was to establish the levels and characteristics of airborne dust to which workers in the furniture industry in High Wycombe are currently exposed. It is clear from the results that dust concentrations vary over a wide range, and thus the level to which a particular worker is exposed may be quite different on consecutive days. In these circumstances the number of samples taken was too few to warrant detailed analysis, but two main conclusions can be drawn:

1. The concentrations of dust in the five factories included in the survey ranged from 1 to $25 \mathrm{mg} \mathrm{m}^{-3}$ with a median of 4.2 and mean of $5.9 \mathrm{mg} \mathrm{m}^{-3}$. These values are similar to the TLV of $5 \mathrm{mg} \mathrm{m}^{-3}$ provisionally recommended by the American Conference of Governmental Industrial Hygienists. A more detailed survey would be required to identify the dustiest occupations in the industry.

2. Most of the mass of the airborne dust has an equivalent diameter in excess of $5 \mu \mathrm{m}$ and will be effectively trapped in the nasal passages on inhalation. Comparatively little of the airborne material can be considered as respirable. Of the machines examined, it appears that sawing produces the coarsest dust and sanding the finest.

In general, considerable attention had been given to the design of extract ventilation on machines. Although provided primarily for the disposal of chippings and coarse dust, its importance for the containment of airborne dust is being increasingly appreciated. Only a few machines were noticed which were not provided with extract ventilation. Among these were high-speed routing machines incorporating means for blowing away from the cutters the chips and particles of wood as permitted in the recent draft Woodworking Machines Regulations (1972). Although the fine particles made airborne in this way may not be inhaled by the operators of the routing machines there must, as a result, be a general increase in the level of dust in the workshop environment. One other obvious source of dust was the use of hand-operated jets for removing dust from machines, wood surfaces, and clothing. Most of these are unsilenced and present a noise hazard as well as producing high local concentrations of dust. Quite high levels of dust can be produced in the conversion shops and other areas when, for example, large planks are dropped onto flat dusty surfaces (e.g., other planks).

Dust respirators were available in all factories and their use is encouraged by management. In general, however, they were worn only during the dustiest operations. While respirators of the patterns provided are not very efficient for fine dust particles (less than $1 \mu \mathrm{m}$ in diameter), when correctly worn they should give adequate protection against dust of the size encountered in machine and assembly shops.

The authors are pleased to acknowledge the full cooperation of both management and union representatives at all the factories visited and the assistance provided by the High Wycombe Furniture Manufacturers Society. They also wish to thank Miss E. H. Hadfield of the Wycombe General Hospital, High Wycombe and Mr. R. G. Macbeth of the High Wycombe and District Furniture Manufacturers Nasal Survey, High Wycombe for their advice and encouragement, and Mr. A. Morgan who supervised this survey. The investigation was supported by the Oxford Regional Hospital Board and the Medical Research Council.

\section{References}

Acheson, E. D., Cowdell, R. H., Hadfield, E., and Macbeth, R. G. (1968). Nasal cancer in woodworkers in the furniture industry. British Medical Journal, 2, 587-596.

American Conference of Governmental Industrial Hygienists (1970). Threshold Limit Values of Airborne Contaminants, 3rd ed., pp. 279-281. Cincinnati, Ohio.

Black, A., Evans, J. C., Hadfield, Esme H., Macbeth, R. G., Morgan, A., and Walsh, M. (1974). Impairment of nasal mucociliary clearance in workers in the furniture industry. British Journal of Industrial Medicine, 31, 10-17.

Findley, L. J. (1972). An unusual case of rosewood dermatitis of the genus Dalbergia (East Indian rosewood). British Journal of Industrial Medicine, 29, 343-344.

Hadfield, Esme H. (1970). A study of adenocarcinoma of the paranasal sinuses in woodworkers in the furniture industry. Annals of the Royal College of Surgeons of England, 46, 301-319.

Hanslian, L. and Kadlec, K. (1964). Drevo a jeho prach (Timber and timber dust). Pracovní Lékařstvi, 16, 276-282.

Hounam, R. F. (1965). An application of the log-normal distribution to some air sampling results and recommendations on the interpretation of air sampling data. UKAEA Unclassified Report AERE-M 1469 (revised).

a device for determining the concentration and size distribution of aerosols. American Industrial Hygiene Association Journal, 26, 122-131.

Michaels, L. (1967). Lung changes in woodworkers. Canadian Medical Association Journal, 96, 1150.

O'Connor, D. T. (1973). Calibration of a cascade centripeter dust sampler. Annals of Occupational Hygiene, 16, 119-125.

Sherwood, R. J. and Greenhalgh, D. M. S. (1960). A personal air sampler. Annals of Occupational Hygiene, 2, 127-132. 
Williams, J. (1972). Dust in the furniture industry. Dissertation submitted for the degree of M.Sc. in the Faculty of Science of the University of London.

Woodworking Machines Regulations (1972). Draft Statutory Instrument. HMSO, London.
Wright, B. M. (1954). A size-selecting sampler for airborne dust. British Journal of Industrial Medicine, 11, 284-288.

Received for publication May 21, 1973

Accepted for publication June 29, 1973 